\title{
Lipid and cholesterol metabolism gene expression in pterygium fibroblasts: comparative analysis with adipocytes and other fibroblasts
}

\section{Expresión de genes del metabolismo de lípidos y colesterol en fibroblastos de pterigión: análisis comparativo con adipocitos y otros fibroblastos}

\author{
Judith Zavala*, Víctor Treviño, Arely A. Reyna-Fuentes, Clarissa M. Arellano-Gurrola, \\ Daniela Enriquez-Ochoa, Jorge L. Domene-Hickman and Jorge E. Valdez-García \\ Tecnologico de Monterrey, Escuela de Medicina y Ciencias de la Salud, Monterrey, Mexico
}

\begin{abstract}
Purpose: To compare the gene expression associated with lipid and cholesterol metabolism in pterygium fibroblasts, adipocytes and other types of fibroblasts. Methodology: Gene expression data from 12 samples of primary pterygium, 12 from adipose cells and 63 from other types of fibroblasts with the same platform were obtained from the gene expression omnibus database. The mean expression for each gene was calculated for each cell type. Differentially and similarly expressed genes were subjected to overrepresentation analysis to obtain signaling pathways, protein interactions, and associated functional terms. Results: Of the 16,511 genes analyzed, 921 differentially and 1,207 similarly expressed were found. From the overrepresentation analysis of differentially expressed genes, 460 genes were found associated $(p<0.05)$ to the SREBP1 protein, while in the similarly expressed genes 615 were found associated to the same protein. The HMGCR, ACOX1 and LRP1 genes showed significantly decreased expression $(p<0.05)$ in pterygium fibroblasts compared to adipocytes and other types of fibroblasts. Expression of the HMGCS gene was significantly higher $(p<0.05)$ in pterygium fibroblasts than in adipocytes and lower than in other fibroblast types. Other genes, including LPL, ACAT1, LSS, LDLR and LCAT showed a differential expression between the three cell types. Conclusion: Deregulated expression of genes associated with lipid and cholesterol metabolism in pterygium fibroblasts is related to proliferation, suggesting further study as potential therapeutic targets.
\end{abstract}

Key words: Pterygium. Adipocytes. Microarrays. Cholesterol. Lipid. Fibroblast.

\section{Resumen}

Propósito: Comparar el nivel de expresión génica asociada al metabolismo de lípidos y colesterol en fibroblastos de pterigión, adipocitos y otros tipos de fibroblastos. Metodología: Los datos de expresión génica de 12 muestras de pterigión primario, 12 de células adiposas y 63 de otros tipos de fibroblastos con la misma plataforma fueron obtenidos de la base de datos Gene Expression Omnibus (GEO). El promedio de expresión para cada gen fue calculado para cada tipo de célula. Los genes diferencialmente y los similarmente expresados se sometieron a análisis de sobrerrepresentación para obtener

Correspondence:

*Judith Zavala

Av. Morones Prieto, 3000

Col. Los Doctores

Date of reception: 23-01-2018

Date of acceptance: 05-07-2018

DOI: 10.24875/RMOE.M18000043

Pu: $10.24875 / R M O E M 18000043$

Available online: 11-01-2019 Rev Mex Oftalmol (Eng). 2019;93(1):3-9 www.rmo.com.mx

0187-4519/@ 2018 Sociedad Mexicana de Oftalmología. Publicado por Permanyer México. Este es un artículo Open Access bajo la licencia CC BY-NC-ND
(http://creativecommons.org/licenses/by-nc-nd/4.0/). (http://creativecommons.org/licenses/by-nc-nd/4.0/) 
vías de señalización, interacciones proteicas y términos funcionales asociados. Resultados: De los 16,511 genes analizados se obtuvieron 921 diferencialmente expresados y 1,207 similarmente expresados. Del análisis de sobrerrepresentación de los genes diferencialmente expresados se encontraron 460 genes asociados $(p<0.05)$ a la proteína SREBP1, mientras que en los genes similarmente expresados se encontraron 615 genes asociados a la misma proteína. Los genes HMGCR, ACOX1 y LRP1 mostraron expresión significativamente disminuida $(p<0.05)$ en fibroblastos de pterigión en comparación con adipocitos y otros tipos de fibroblastos. La expresión del gen HMGCS fue significativamente mayor $(p<0.05)$ en fibroblastos de pterigión que en adipocitos y menor que en otro tipo de fibroblastos. Otros genes, incluidos LPL, ACAT1, LSS, LDLR y LCAT mostraron diferencia de expresión entre los tres tipos celulares. Conclusión: La expresión desregulada de genes asociados al metabolismo de lípidos y colesterol en fibroblastos de pterigión está relacionada con la proliferación, sugiriendo su estudio posterior como posibles blancos terapéuticos.

Palabras clave: Pterigión. Adipocitos. Microarreglos. Colesterol. Lípidos. Fibroblastos.

\section{Introduction}

Pterygium is an abnormal cellular growth in the conjunctiva with tumor characteristics, among which uncontrolled growth, invasion and migration stand out. Its occurrence is associated with prolonged sun exposure. It has an incidence of up to $10 \%$ in populations near the equator. It is benign in nature; however, its growth and migration to the central region of the eye can interfere with the visual field, as well as cause irritation, inflammation and induce astigmatism ${ }^{1}$.

Although the mechanisms underlying the pathogenesis of pterygium are not completely understood, its development is associated with exposure to ultraviolet (UV) light. Several factors have been related to the pathogenesis of pterygium, including epigenetic factors, inflammation mediators, growth factors, extracellular matrix modulators, angiogenic and lymphangiogenic factors, immunological mechanisms and cholesterol metabolism alterations ${ }^{2}$.

The only treatment available for pterygium removal is surgery, with the disadvantage of recurrence. The most sophisticated surgical techniques use conjunctival or amniotic membrane autografts to cover the conjunctival area from which the pterygium is removed, aiming to obtain better aesthetic results and to reduce the recurrence rate. The postoperative use of antimetabolites, such as mitomycin- $\mathrm{C}$ and beta-radiotherapy, are also used as adjuvants in the prevention of recurrence ${ }^{3}$.

Research on the pathogenesis of pterygium with the use of in vitro models has provided information on the underlying molecular mechanisms and thus possible therapeutic targets. It has been shown that in human pterygium, cholesterol metabolism is accelerated and that, when antiproliferative agents are applied to pterygium, cholesterol metabolism decreases ${ }^{4}$. Similarly, it has been found that fibroblasts from pterygium have an increase in the cholesterol esterification process that leads to an increase in the proliferation rate ${ }^{5}$. Given that adipose tissue is the main storage and metabolism site of lipids and cholesterol, the analysis of common pathways between this tissue and pterygium would provide more information about its pathogenesis and possible therapeutic targets. In addition, comparison with another type of fibroblasts would provide information on the specific characteristics of pterygium fibroblasts.

\section{Purpose}

The objective of this study was to compare the gene expression associated with lipid and cholesterol metabolism between pterygium fibroblasts, adipocytes and other types of fibroblasts and to identify the associated signaling pathways.

\section{Methodology}

Data on the gene expression pattern of 8 samples of primary pterygium (GSE2513, without using conjunctiva), 12 of adipocytes (GSE39117, specifically pre-LPS T1) and 63 of other types of fibroblasts from different body tissues (GSE63626, which contains 3 from blood vessels, 4 from chest, 8 from colon, 6 from duodenum, 6 from esophagus, 3 from gallbladder, 6 from ileum, 5 from liver, 3 from lung, 7 from mammary gland, 3 from prostate, 6 from stomach, and 3 from uterus). All data were tested with the same platform (Affymetrix Human Genome U133) and were obtained from the Gene Expression Omnibus (GEO) database of the National Center for Biotechnology Information (NCBI). Data were normalized by transforming them to a uniform distribution between 0 and 1 before the analysis. Zero indicates absent or very low expression and 1 indicates maximum expression. 
Table 1. Associated terms $(p<0.05)$ to differentially expressed genes between adipocytes and pterygium fibroblasts obtained by overrepresentation analysis with the DAVID tool

\begin{tabular}{|c|c|c|c|}
\hline Category & Term & $\begin{array}{l}\text { Number of } \\
\text { associated genes }\end{array}$ & Examples of associated genes \\
\hline Protein interactions (UCSC_TFBS) & SREBP1 & 460 & $\begin{array}{l}\text { Stard5, LPL, FADS3, LYPLA2, SREBF1, LRP1 } \\
\text { LRP5, NEDD4 }\end{array}$ \\
\hline \multirow[t]{3}{*}{ Functional category (UP_Keywords) } & Lipoproteins & 46 & AKAP7, LRP1, APOC1, CPM, LPL, LDLRAP1 \\
\hline & Lipid metabolism & 26 & $\begin{array}{l}\text { NPC1, ACADL, ACOX1, ACSM5, CROT, } \\
\text { CPT1A, EHHADH, FADS3, LPL, LDLRAP1, } \\
\text { LYPLA2, MVK, SREBF1 }\end{array}$ \\
\hline & Fatty acid metabolism & 10 & $\begin{array}{l}\text { ACADL, ACOX1, ACSM5, CROT, CPT1A, } \\
\text { EHHADH, FADS3, LYPLA2, PECR, PTGES }\end{array}$ \\
\hline
\end{tabular}

Gene expression data were analyzed in Excel. Intersection regions between the expression studies were obtained by the VLOOKUP function, creating a matrix with the same genes analyzed in both tissues together with their expression value for each sample. Subsequently, the data were normalized using the RANK. EQV function of Excel, to assign the same hierarchy to the values used. The average expression for each gene was calculated for adipocytes, pterygium fibroblasts and other types of fibroblasts. The difference in expression, established as the subtraction of the average expression of pterygium fibroblasts and adipocytes for each gene, was calculated and then compared with the average expression of other types of fibroblasts.

We performed a statistical analysis of the expression difference of each gene using the Student's t-test with the normalized values of the different cell types. The expression difference was analyzed to establish the expression difference interval and the value of the T-student test in which there is a greater relationship. The range of the difference in expression was established using an absolute difference greater than 0.4 and a $p$ $<1 \times 10^{-7}$. The range of expression similarity was bounded with a $p>0.5$ and an absolute difference in expression level $<0.05$.

The overrepresentation analysis of genes similarly and differentially expressed between pterygium fibroblasts and adipocytes was done using the Gene Functional Classification Tool of DAVID Bioinformatics Resources ${ }^{6,7}$ to obtain the terms of ontology, signaling pathways and associated protein interactions. The genes representative of the lipid and cholesterol metabolism pathways were searched in the gene matrix in the different cell types to compare their expression level.

\section{Results}

\section{Genes differentially expressed between adipocytes and pterygium fibroblasts}

Of the 16,511 genes analyzed, 921 were obtained with a $p$ value $<1 \times 10^{-7}$ and an absolute difference of $>0.4$. The overrepresentation analysis with the DAVID tool provided information about the associated terms. The terms with the greatest number of associated genes represented those of constitutive processes: transcription factors, cell cycle, cell membrane, etc. (data not shown). Those terms associated with a $p<0.05$ specific value of lipid metabolism were recorded (Table 1). No cholesterol and lipid metabolic pathways were found to be significantly associated with differentially expressed genes. The metabolic pathways that presented a significant association were: cancer pathways (48 genes), PI3K-Akt (31 genes), proteoglycans in cancer (28 genes) and MAPK pathway (26 genes).

\section{Genes similarly expressed between adipocytes and pterygium fibroblasts}

We obtained 1,207 similarly expressed genes ( $p>0.5$ and absolute difference $<0.05$ ). When performing the overrepresentation analysis, the terms SREBP1 and lipid binding related to lipid metabolism were found (Table 2).

\section{Gene expression associated with lipid and cholesterol metabolism in adipocytes, pterygium fibroblasts and other types of fibroblasts}

The expression levels of the ACOX1, HMGCR, HMGCS and LRP1 genes, specific for lipid metabolism, were analyzed within the data matrix. It was observed 
Table 2. Associated terms $(p<0.05)$ to similarly expressed genes between adipocytes and pterygium fibroblasts obtained by overrepresentation analysis with the DAVID tool

\begin{tabular}{|l|l|c|l|}
\hline Category & Term & $\begin{array}{c}\text { Number of } \\
\text { associated genes }\end{array}$ & Examples of associated genes \\
\hline Protein interactions (UCSC_TFBS) & SREBP1 & 615 & ELOVL4, LRP8, CRAT, CPT1A, CPT2, ECH1, FFAR2, LDAH \\
\hline Functional category (UP_Keywords) & Lipid binding & 19 & FFAR2, PGRMC1, ERLIN1 \\
\hline
\end{tabular}

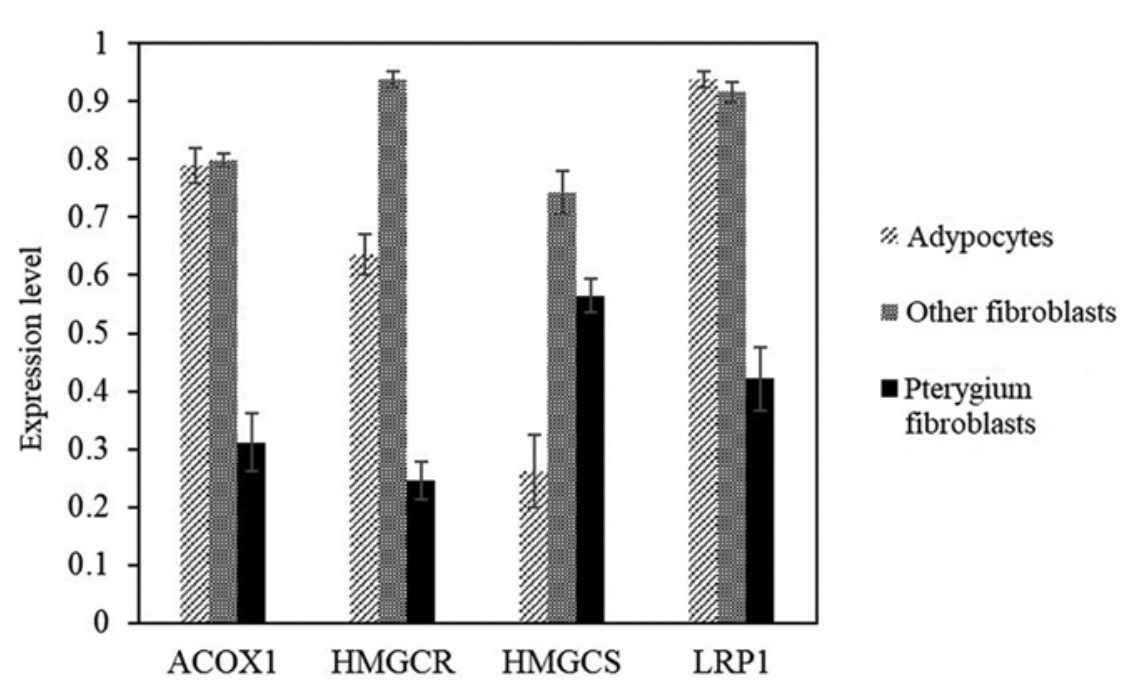

Figure 1. Comparison of the expression levels of the ACOX1, HMGCR, HMGCS and LRP1 genes between adipocytes, pterygium fibroblasts and other types of fibroblasts.

that the four genes show a higher level of expression $(p<0.05)$ in other types of fibroblasts compared to pterygium fibroblasts. The HMGCS gene showed a higher level of expression in pterygium fibroblasts compared to adipocytes, with a $p$ value $<0.05$. Fibroblasts of other types showed higher expression of this gene compared to adipocytes and pterygium fibroblasts. The ACOX1 and LRP1 genes showed no significant difference in the expression level between adipocytes and other types of fibroblasts $(p>0.05)$ (Fig. 1).

We also compared the averages of the expression levels of additional genes related to lipid metabolism between each cell type, generating a heat map (Fig. 2). In general, it was observed that the expression of genes associated to lipid and cholesterol metabolism has a greater similarity between adipocytes and other types of fibroblasts. The genes with the greatest difference in the expression level in pterygium fibroblasts compared to adipocytes and other fibroblasts were FADS2, FADS3, HMGCR, LPL and APOC1. The LDLRAD4, ACOT1, ACOX1, LRP1 and APOE genes showed no significant difference in the expression level between adipocytes and other fibroblasts $(p>0.05)$

\section{Discussion}

The overrepresentation analysis of genes with similar and different expression between adipocytes and pterygium fibroblasts showed a large number of genes associated with constitutive processes: transcription factors, cell cycle, cell membrane, and so on. When conducting the search focused on cholesterol and lipid metabolism, we found terms with a significant association with a much lower gene count. Of the differentially expressed genes, more terms were obtained with a significant association to lipid metabolism compared to the similarly expressed genes. The main term associated with both genes similarly and differentially expressed between pterygium fibroblasts and adipocytes was SREBP1.

This gene codes for the transcriptional activator required for lipid homeostasis, regulating the transcription of the low-density lipoprotein (LDL) receptor and the synthesis of fatty acids and cholesterol. Tong, et al. ${ }^{8}$ reported that the expression of SREBP1 in pterygium is greater than that observed in healthy conjunctiva. In our analysis, the SREBP1 gene was significantly 


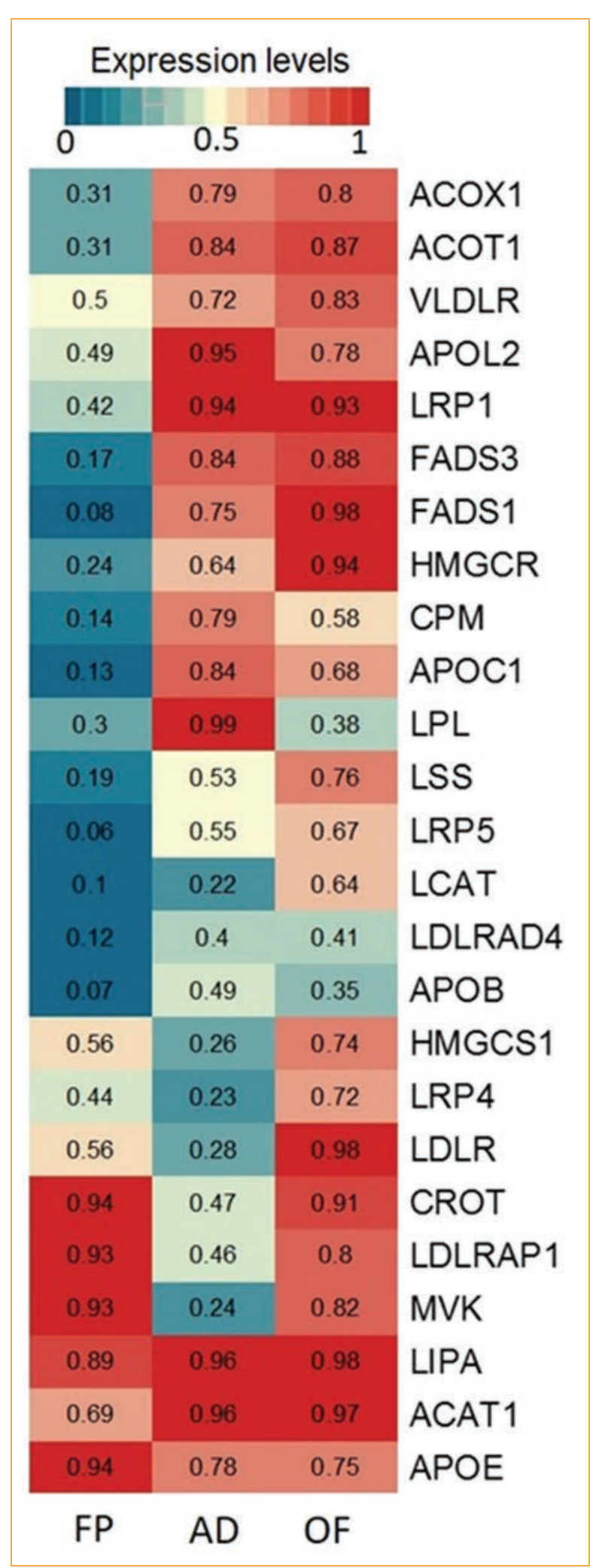

Figure 2. Map comparing the expression level of genes associated with lipid and cholesterol metabolism. $\mathrm{AD}$ : adipocytes; PF: pterygium fibroblasts; OF: other fibroblasts. increased in pterygium fibroblasts compared to adipocytes, but with the same expression as observed in other types of fibroblasts.

From the comparative analysis of the expression level of genes associated with lipid and cholesterol metabolism between pterygium fibroblasts, adipocytes and other fibroblasts, four fundamental dysregulated genes were found: ACOX1, HMGCR, HMGCS and LRP1. Of these, only HMGCS showed a higher expression in pterygium fibroblasts compared to adipocytes. In a previous study, Peiretti, et al. ${ }^{9}$ showed that HMGCR, a limiting enzyme in the pathway of cholesterol synthesis, is overexpressed in pterygium compared with pinguecula and healthy conjunctiva. In our analysis, the HMGCR gene had lower expression level in pterygium fibroblasts compared to adipocytes and other fibroblasts.

The ACOX1, HMGR and LRP1 genes had a lower average expression level in pterygium fibroblasts compared to adipocytes. The expression of ACOX1 and LRP1 did not show a significant difference between adipocytes and other fibroblasts. The enzyme ACOX1 is the first enzyme in the beta-oxidation pathway of fatty acids; its decrease causes adrenoleukodystrophy, a disease in which there is accumulation of very long chain fatty acids ${ }^{10}$. HMGCR is the limiting enzyme in cholesterol biosynthesis and its expression is directly proportional to its serum levels ${ }^{11}$. It has been demonstrated that the inactivation in mice of LRP1, the producer gene of the low-density lipoprotein receptor $\mathrm{T}$, leads to dyslipidemia and atherosclerosis ${ }^{12}$.

The HMGCS1 gene showed a higher or lower order of expression level in other fibroblasts > pterygium fibroblasts $>$ adipocytes. The difference in the levels of expression was significant. This gene codes for the enzyme HMGCS1, which produces HMG-CoA at the critical step in the cholesterol biosynthesis pathway. It has been shown that the increased regulation of this enzyme leads to a high synthesis of lipids and weight gain $^{13}$. The genes of the MVK and LSS enzymes, which also participate in the cholesterol synthesis pathway, showed a different expression in the three cell types. The MVK gene had a higher expression in pterygium fibroblasts, other fibroblasts and adipocytes. While the LSS gene was found with a lower expression compared to adipocytes and other fibroblasts. Overall, the deregulation of gene expression of the enzymes associated with cholesterol synthesis explains the overproduction reported by Peiretti ${ }^{4}$. 
Among the genes analyzed, differences in expression were also found in those coding for lipoprotein metabolism enzymes. The APOB, APOC1 and APOL2 genes were found to have a significantly decreased expression in pterygium fibroblasts compared to adipocytes and other fibroblasts, while the APOE gene was overexpressed. APOB is the main protein component of chylomicrons (apoB-48), LDL and very low-density lipoproteins (VLDL) (apoB-100). Mutations of this gene lead to deregulated levels of LDL in blood and hypercholesterolemia ${ }^{14}$. The deregulation of the expression of APOC1 and APOL1 genes is also related to the development of triglyceridemia ${ }^{15,16}$. It is known that APOE mediates cholesterol metabolism and different isoforms are associated with hyperlipidemia and hypercholesterolemia ${ }^{17}$. LRP1 is the producer gene of LDL receptor 1. This receptor is involved in the intracellular signaling and endocytosis of lipoproteins. It has been demonstrated that the inactivation of this gene in mice leads to dyslipidemia and atherosclerosis ${ }^{12}$. The analysis showed a significantly reduced expression of this gene in pterygium fibroblasts compared to adipocytes and other fibroblasts, which correlates with the increase in cholesterol metabolism already described.

The expression levels of the LPL, LCAT, FADS1 and FADS3 genes were significantly decreased in pterygium fibroblasts compared to adipocytes and other fibroblasts. These genes code for enzymes that participate in the homeostasis of cholesterol and fatty acids. Lipoprotein lipase (LPL) hydrolyzes triglycerides, producing free fatty acids and glycerol. It has been demonstrated that the deficiency of this enzyme leads to hyperlipoproteinemia and hypertriglyceridemia ${ }^{18}$. Lecithin cholesterol acyltransferase (LCAT) converts free cholesterol to cholesterol esters, the hydrophobic form of cholesterol that is part of lipoproteins. LCAT deficiency is associated with increased levels of cholesterol bound to high-density lipoproteins (HDL) and hypertriglyceridemia $^{19}$. The enzymes FADS1 and FADS3 desaturate fatty acids producing polyunsaturated fatty acids, which are essential in humans; their deregulation has been associated with hyperlipidemia ${ }^{20-22}$.

The ACOT1 gene showed a decreased expression in pterygium fibroblasts. This gene codes for the enzyme acyl-CoA thioesterase, which regulates the intracellular levels of CoA esters, coenzyme $A$ and free fatty acids. A functional relationship has been suggested between the levels of this enzyme and fatty acid oxidation, and that the regulation of ACOT1 is an adaptive response as a protection against fatty acids overproduction ${ }^{23}$.
The expression of ACOT1 was similar between adipocytes and other fibroblasts.

In general, deregulation of the analyzed genes provides a broader picture of the mechanisms underlying the cholesterol increase observed in pterygium, which in turn relates to the increase in cell proliferation characteristic of this pathology.

\section{Conclusions}

Pterygium is an abnormal growth in the conjunctiva that can only be treated with surgical removal. Although this treatment improved until the development of auto conjunctival grafts and amniotic membrane, recurrence has not yet been completely prevented. This health problem is specifically important in regions near the equator, where the incidence is greater due to exposure to UV rays.

The study of its pathogenesis has reported that cholesterol is one of the deregulated pathways in pterygium, which contributes to the mechanism of deregulated proliferation. This provides tools for the identification of therapeutic targets for the reduction, elimination or prevention of pterygium recurrence.

In this sense, analysis of the gene expression pattern by microarrays and analysis by proteomics of pterygium have been reported. However, the amount of information obtained from these analyses is extensive and the identification of important routes can take a long time. In these analyses, pterygium gene expression is compared to that of healthy conjunctiva. In this analysis, the deregulation of the HMGCR gene previously reported in pterygium was corroborated and its level of expression was compared for the first time with adipocytes and other fibroblasts. The additional analysis of genes associated with cholesterol and lipoprotein metabolism showed that pterygium fibroblasts have a different expression pattern compared to other types of fibroblasts and adipocytes; the latter two have a similar expression pattern for this type of genes. To date, no similar reports have been found. The knowledge about deregulated lipid pathways in pterygium provides tools for the study of its pathogenesis and for the analysis of possible pharmacological therapeutic targets.

\section{Ethical disclosures}

Protection of human and animal subjects. The authors declare that no experiments were performed on humans or animals for this study. 
Confidentiality of data. The authors declare that no patient data appear in this article.

Right to privacy and informed consent. The authors declare that no patient data appear in this article.

\section{Conflicts of interest}

The authors declare that there is no conflict of interest in the development of this research work.

\section{References}

1. Mohammed I. Treatment of pterygium. Ann Afr Med. 2011;10:197-203.

2. Cardenas-Cantu E, Zavala J, Valenzuela J, Valdez-Garcia JE. Molecular Basis of Pterygium Development. Semin Ophthalmol. 2016;31:567-83.

3. Hacioglu D, Erdol H. Developments and current approaches in the treatment of pterygium. Int Ophthalmol. 2017;37:1073-81.

4. Peiretti E, Dessi S, Mulas MF, Abete C, Galantuomo MS, Fossarello M Fibroblasts isolated from human pterygia exhibit altered lipid metabolism characteristics. Exp Eye Res. 2006;83:536-42.

5. Galantuomo M, Mulas MF, Baire P, Abete C, Peiretti E, Dessì S, et al Proliferative Activity and Cholesterol Ester Metabolism in Primary Culture of Human Pterygium Fibroblasts. Invest Ophthalmol Vis Sci. 2005;46:960.

6. Huang DW, Sherman BT, Lempicki RA. Bioinformatics enrichment tools: paths toward the comprehensive functional analysis of large gene lists. Nucleic Acids Res. 2009;37:1-13

7. Haung DW, Sherman BT, Lempicli RA. Systematic and integrative analysis of large gene lists using DAVID bioinformatic resources. Nat Protoc. 2009;4:44-57.

8. Tong L, Chew J, Yang H, Ang LPK, Tan DTH, Beuerman RW. Distinct gene subsets in pterygia formation and recurrence: dissecting complex biological phenomenon using genome wide expression data. BMC Med Genomics. 2009;2:14

9. Peiretti E, Dessi S, Putzolu M, Fossarello M. Hyperexpression of low-density lipoprotein receptors and hydroxy-methylglutaryl-coenzyme A-reduc- tase in human pinguecula and primary pterygium. Invest Ophthalmol Vis Sci. 2004;45:3982-5.

10. Shimozawa N. Molecular and clinical aspects of peroxisomal diseases. J Inherit Metab Dis. 2007;30:193-7.

11. Arnaud C, Veillard NR, Mach F. Cholesterol-independent effects of statins in inflammation, immunomodulation and atherosclerosis. Curr Drug Targets Cardiovasc Haematol Disord. 2005:5:127-34.

12. Gordts PL, Reekmans S, Lauwers A, Van Dongen A, Verbeek L, Roebroek AJ. Inactivation of the LRP1 intracellular NPXYXXL motif in LDLR-deficient mice enhances postprandial dyslipidemia and atherosclerosis. Arterioscler Thromb Vasc Biol. 2009;29:1258-64.

13. Raeder MB, Ferno J, Glambek M, Stansberg C, Steen VM. Antidepressant drugs activate SREBP and up-regulate cholesterol and fatty acid biosynthesis in human glial cells. Neurosci Lett. 2006;395:185-90.

14. Farese RV Jr, Linton MF, Young SG. Apolipoprotein B gene mutations affecting cholesterol levels. J Intern Med. 1992;231:643-52.

15. Berbée JFP, van der Hoogt CC, Sundararaman D, Havekes LM, Rensen, PCN. Severe hypertriglyceridemia in human APOC1 transgenic mice is caused by apoC-I-induced inhibition of LPL. J Lipid Res. 2005;46:297-306.

16. Duchateau PN, Movsesyan I, Yamashita S, Sakai N, Hirano KI, Schoenhaus $S A$, et al. Plasma apolipoprotein L concentrations correlate with plasma triglycerides and cholesterol levels in normolipidemic hyperlipidemic, and diabetic subjects. J Lipid Res. 2000;41:1231-6.

17. Mahley RW, Rall SC Jr. Apolipoprotein E: far more than a lipid transport protein. Annu Rev Genomics Hum Genet. 2000:1:507-37.

18. Okubo M, Horinishi A, Saito M, Ebara T, Endo Y, Kaku K, et ar. A novel complex deletion-insertion mutation mediated by Alu repetitive elements leads to lipoprotein lipase deficiency. Mol Genet Metab. 2007:92:229-33.

19. Ossoli A, Simonelli S, Vitali C, Franceschini G, Calabresi L. Role of LCAT in Atherosclerosis. J Atheroscler Thromb. 2016;23:119-27.

20. Hastings N, Agaba M, Tocher DR, Leaver MJ, Dick JR, Sargent JR. A vertebrate fatty acid desaturase with $\Delta 5$ and $\Delta 6$ activities 2001;25: 14304-9.

21. Plaisier CL, Horvath S, Huertas-Vazquez A, Cruz-Bautista I, Herrera MF, Tusie-Luna T. A systems genetics approach implicates USF1, FADS3, and other causal candidate genes for familial combined hyperlipidemia. PLoS Genet. 2009;5:e1000642.

22. Huang MC, Chang WT, Chang HY, Chung HF, Chen FP, Huang YF, et al. FADS Gene Polymorphisms, Fatty Acid Desaturase Activities, and HDL-C in Type 2 Diabetes. Int J Environ Res Public Health. 2017;14:E572.

23. Fujita M, Momose A, Ohtomo T, Nishinosono A, Tanonaka K, Toyoda H, et al. Upregulation of fatty acyl-CoA thioesterases in the heart and skeletal muscle of rats fed a high-fat diet. Biol Pharm Bull. 2011;34:87-91. 